\title{
Class Room Level Motivation and Follow up and its Effects on Second Language Acquisition: A Study
}

\author{
Sambhunath Maji* \& Prof. Birbal Saha** \\ *Research Scholar, Department of Education, Sidho-Kanho-Birsha University, WB. \\ ** Professor, Department of Education, Sidho-Kanho-Birsha University, WB.
}

DOI: 10.29322/IJSRP.10.06.2020.p10289

http://dx.doi.org/10.29322/IJSRP.10.06.2020.p10289

\begin{abstract}
Modern day classroom is the busiest and event-driven destination for the learners, where they remain engaged and involve every single moment either in getting new lessons from classroom teacher or their motivational works or talks. As per the role of classroom teacher in modern day scenario is concerned, it is very specialized and directed. Each one is devoted for one particular subject or topic. In language and literature classroom, the picture offers many levels of cognitive workings of the learners' mind. A teacher, who is dedicated in literature classroom, teachers the subject, but automatically language learning instruction and motivation come in the due course. Whether in arranged or casual condition the teacher is convinced with the fixed belief that a learner can best swallow the textual and subject knowledge, having sufficient mastery in the relevant language. This research article will readdress if classroom level motivation for Second Language Acquisition can further be extended at the follow up program. The investigation will also get an idea if motivation and follow up motivation program are good enough to prolong the interest level of the language learners. The investigator is also trying to get an air if this classroom level motivation be lifted at follow up level, and if this follow up motivation can be sustained for long.
\end{abstract}

Key Words: Classroom Level Motivation, Follow up, Second Language Acquisition, Sustained Interest

\section{Introduction:}

Second Language Acquisition is the most widely used word of the last four or five decades. Several studies are conducted to cultivate more substantial knowledge in the respective field. Such studies reveal that Second Language Acquisition can take place in the schools, colleges, universities, clubs, pub-houses and streets (Macaro, 2010). One learns the Second Language with friends, relatives and other family members. The course second language acquisition is not smooth and linear. There appear many hurdles in the way. As a result, learning atmosphere is as important as the learning itself. The second language acquisition introduces the obstacles which are of two kinds: external and internal. The external factors involve the issues like influence of native language, cross-linguistic effects, age, learning atmosphere etc. whereas the internal factors are also variegated such as aptitude, attitude, motivation, metacognition and cognition, ability to handle cross-linguistics influence etc. The investigator of the study has decided to go with motivation of Second Language Acquisition and its follow up in normal classroom condition. The investigator is also well-equipped with the modern day classroom which is always prone to become multicultural in landscape. The challenges of such classroom are many. Still, motivation is vouchsafed as an important factor in Second Language Acquisition. The intervening effect of mother tongue is a significant complication in Second Language Acquisition. The matrix gets more complicated if the classroom offers multicultural ambience. The intervening or overlapping effects of the mother language of the learners emerge as one crucial aspect of cross-linguistic effects. In such a situation, the role of teacher and the approaches of the second language learners really become very relevant field for exploration. The investigator of the study aims to get an idea how motivation and its follow up really works in Second Language Acquisition in multicultural classroom situation with cross-linguistic overlapping. 


\section{Defining Motivation and its Follow Up:}

MacMillan Dictionary (2019) defines motivation as "a feeling of enthusiasm or interest that makes you determined to do something". Gardner (1985) explained motivation as "combination of efforts plus desire to achieve the goal of learning language plus favourable attitudes toward learning the language". Mukherjee (2009) cited motivation as an urge "which is created because of the absence of something desirable for the organism". Leaver et al. (2005) note that motivation is behind all the choices you make and everything you do. They classified motivation as intrinsic and extrinsic. They also accepted the overlapping tendency of the two. It may be that one cannot make the proper timing when these overlap one another. As their observation goes, motivation emerges as an extrinsic in nature like other aspects. They noted that "extrinsic motivation has to do with doing something for such 'outside' reasons as money, job requirements, or passing a test'. Loewen and Reinders (2011) defined motivation as "psychological construct that refers to the desire and incentive that an individual has to engage in a specific activity". They further note that "in the study of Second Language Acquisition, motivation has been considered as an important area of investigation because it has been assumed that increased motivation will result increased learning". Emmons and King (1988) pointed a notable aspect of motivation. They claimed motivation as "force underlying pattern". They further quote motivation as "an interest in recurrent pattern". This recurrent pattern keeps its flow through proper impulses and strategical approach. For the present study, the investigator has thought it proper that follow up programme for motivation is the best and effective strategical approach that classroom teacher can arrange without facing much hazards and expense. A teacher, in a classroom situation, can address the issues of follow up programme in the most explicit terms. In this present study, the researcher only counts the classroom level motivation and the follow up of the same motivation by the classroom for the second language acquisition of the learners. The researcher of the study will remain equally watchful to factors that contribute spontaneously in second language acquisition and follow up programme in teacher-controlled classroom. Follow up programme directs task and next day follow up activities. These also involves issues like task, next day follow up, determination to carry the same, proper decision making, realtime observation of the progress in task and real-time exit from the same. According Jill Baker (2012), follow up offers a regulatory authority. In this present study, the classroom teacher is going to execute all these formalities to conduct accurate follow up of the motivation for second language acquisition.

\section{Significance of the Study:}

Second Language Acquisition is now the practical need of the hour irrespective of gender and demographical diversity. Though it begins at home, the systematic acquisition of the second language becomes possible at our educational institution. While pursuing particular courses, this systematic acquisition process remains on. Along with day to day progress of the study the learner cultivates new vocabulary and newer syntactic structures. The speed of second language acquisition largely varies depending upon the various factors like individual difference, environmental effects, socio-economic condition and metacognitive practices. Classroom Level Motivation and Follow Up are the most effective individual differences that really contribute to the smoother acquisition of second language along with their parallel learning of the subject knowledge. The researcher of the study is a teacher of English Literature at P.G. level. After the observation of long seven years, the researcher has decided to put the matter in black and white through systematic procedure. The researcher hopes that his observation and proper understanding of the problem will help him to suggest the learners so that they get much quicker in cultivating fluency in the second language.

\section{Objectives of the Study:}

Any kind of rational query must proceed with some objectives in the mind. The researcher has the following objectives for the current investigation: 
$\checkmark$ To get an idea of the motivation that the learners receive in ordinary classroom situation.

$\checkmark \quad$ To explore if classroom level motivation can be extended as follow up program for engaging the mind of learners in Second Language Acquisition.

$\checkmark \quad$ To examine if the classroom level motivation and follow up program can prolong the interest level of the learners for Second Language Acquisition.

$\checkmark \quad$ To explore the possibility if this interest can be sustained for long and can be redirected for flawless Second Language Acquisition.

$\checkmark \quad$ To understand the need of the learners so that they can avail true class level motivation.

$\checkmark$ To develop some suggestions that would enable learners to acquire second language in quicker span of time through proper classroom level motivation.

\section{Research Questions:}

The researcher has designed some questions for the smooth conduction of the study:

i. Does modern day classroom centric teaching habit develop any motivation for the language learning among the learners?

ii. Is the assigned classroom teacher transforming his role from teacher to motivator that would create enthusiasm among the learners?

iii. Is the classroom centric reading habit becoming a follow up kind of mind set up for the learners that makes them feel safe and confident about Second Language Acquisition?

iv. Can this classroom generated motivation be prolonged ?

v. Can this classroom inspired motivation and its immediate follow up effect be sustained?

\section{Review of Related Literature:}

In their study Carrio-Pastor and Mestre(2013) highlighted that motivation plays a pivotal role in determining the needs and expectations of the language learners. The study further showed that the students after due motivation displayed the strongest urge for target language. Alizadeh (2016) pointed that motivation of the learners can go up and down depending on the context of language learning. They also mentioned that motivation can enhance the language learning skills of the learners and teachers can play decisive role in motivating the learners through skill development. Mahadi and Jafari (2012) revealed that teachers and lecturers can pay adequate attention in exploring the personality of language learners. They also highlighted that character exploration and personality moulding can prove as one of the decisive factors behind language learning motivation of the students. Oxford and Nyikos (1989) reported that motivation functions as an indicator of the strategy use by the second language learners. Schmidt et al. (1996) revealed that instrumental motivation was so strong among the Egyptian language learners who expectancy was high and determination was incorrigible. Bernaus (1995) reported that teacher has significant role in motivating the second language learners. The study also pointed that there is significant correlation between the motivation of students and their foreign language learning. Gomleksiz (2001) conducted a study on second language acquisition and role of motivation. The investigator reported that motivated learners are more successful in second language acquisition that the learners who received no such motivation. Liu and Wang (2017), in their study on "Motivation, Learning Strategies, and Language Competency in a Technology Facilitated Chinese as a Second Language Classroom", noted that motivation and learning strategies are positively related. Saito et al. (2017) conducted a longitudinal study on the relationship between motivation and late Second Language Speech Learning in Classroom Settings. The study revealed that the students who were motivated for a long term goal showed strongest level of motivation in Second Language Speech Learning. 
Research Methodology:

\section{Population of the Study:}

The researcher, during the designing of the study, has categorically has chosen a segment of mankind, which is known as population. Any research output cannot be separately treated from target group. All the P.G. students of Sidho-Kanho-Birsha University of West Bengal are considered to be population of the study.

\section{Sample and Sampling:}

Research problem is always related to a large population. The aim of a research is to reach at a generalized finding that would be applicable to the large population chosen earlier. Researcher does not get adequate time to collect all the empirical evidences of the entire population. Hence, sampling is the easiest tool that researcher looks for. A sample is a small section of the population. It is generally believed that sample is the representative sub-group of the population. In the present study, the researcher has chosen to go with 100 P.G. students of Sidho-Kanho-Birsha University of West Bengal, who has chosen business English as their open elective subject.

\section{Development of the Tools:}

The investigator of the study has developed a record card to track the various activities of the participants like Attendance, Note Taking, Classroom Interaction, Task-based Approach, Outside Classroom Interaction, Flexibility shown for Correction, Additional Queries to Consult Relevant Book. Attendance was seriously taken in count as a mark of seriousness on the regularity of the participants. Note Taking during the motivation is another important dimension of the follow up program that would denote serious and effective cognitive involvement of the participants. Classroom Interaction was also recorded as a part of verbal participation of the learners. Task-based Approach indicates the level of curiosity of the learners to work out a problem regarding their second language acquisition. The investigator also made a note on Outside Classroom Interaction of the second language learners on relevant subject. The researcher also maintained a record on Flexibility shown for Correction by the second language learners during motivational sessions. Lastly, the investigator also maintained a note on Additional Queries to Consult Relevant Book for second language acquisition.

\section{Data Collection Procedure:}

Various activities of the participants like Attendance, Note Taking, Classroom Interaction, Task-based Approach, Outside Classroom Interaction, Flexibility shown for Correction, Additional Queries to Consult Relevant Book are recorded for six successive weeks before and after the motivational sessions. A monitoring sheet was also maintained to record the all important aspects of study.

\section{Analysis and Discussion:}

The investigator of the present study maintained a monitoring sheet. The close examination of the monitoring sheet shows that attendance in the second language motivation class was increasing when it was carried for six weeks. The attendance of female students was noticeable higher than their male counterparts. The reason behind the absentia of the male students in the second language motivation class may that same teacher was the doing similar kind of work out. It may that they generally receive second language learning motivation from their other classes. When individually approached, the female learners asserted that they regularly attend the second language motivation class because this will bring fluency to their utterance and it will also boost their career opportunities. The monitoring sheet and randomly taken individual interview disclose that the sincerity of the female 
learners is higher than male in regard to second language motivation. The investigator of the present study maintained a note throughout this entire six weeks second language motivation class. The second important thing that was taken into count was note taking of the second language learners in the classroom level motivation scenario. In the first week of the classroom motivation regarding second language acquisition, almost majority of the learners were busy in note taking. This continued even for second and third of the motivation. In the final week of the motivation, learners were busy in listening the classroom level motivational utterances, but they were not taking notes. This can be because of their increasing confidence and enthusiasm.

Classroom Interaction of the learners was also recorded on the regular basis. In the first two weeks of the second language motivation class the learners remained callous and passive listener. They did not ask much. May be they did not have the courage ask or interrogate. In the succeeding weeks the learners were getting interested about the second language. They were asking questions even the inside classroom situations. In this case also, the participation of the female learners was noticeably higher than male. The outside classroom interaction is another aspect that investigator kept in record. The interaction of male students was higher in outside classroom scenario. The reason may be to save the self-esteem. Some hesitation works among the male students. The thing that they did not ask in classroom scene, they asked the same outside the classroom at ease. In regard to inside and outside classroom interaction, the students who opted English as major were the majority. The students of other subjects like Mathematics, Physics and Chemistry did not approach the classroom teacher in either condition.

Task-based Approach and Flexibility shown for Correction were two important dimensions of this study. The observation of the six successive shows that majority of the learners in second language motivation class were very sincere and serious in regard to their classroom task. They sincerely endeavoured to follow the instruction of the assigned teacher, and took notes. During evaluation of their tasks, they showed enough flexibility for correction. They displayed their enthusiasm for self-rectification. In this case, their approach was really praiseworthy and noticeable. Lastly, Additional Queries to Consult Relevant Book was the final issue that was studied seriously. The learners in the second language motivation classroom displayed huge enthusiasm for list books and purchasing these for the self-improvement. The most important finding of the study is the flexibility of the learners for self correction. They were fully dedicated for correction and the improvement of their second language. The enthusiasm shown by the learners for book recommendation by the assigned teacher was an indicative of their growing enthusiasm for second language learning through self correction and self learning.

\section{Conclusion:}

In hindsight, the study regarding second language acquisition and its research in classroom-based condition would open up many such possibilities. The present study shows that motivation in classroom situation has emerged as one of the major individual differential factors of second language acquisition. The degree of motivation that each learner received is largely different from one learner to another. Simultaneously, other related factors also came into function like their individual goal in life, professional awareness of their career, level of sincerity for second language learning etc. As this study was conducted in classroom scenario on regular and weekly basis, this gave the investigator to note each silent and related factor of second language acquisition. The study also creates an opportunity for the investigator to identify the slow motivated or less motivated second language learner. In the normal classroom condition, the investigator-teacher has scope to invite curing strategy for the less motivated learners. The greatest benefit of such classroom centric study is that the teacher investigator can show essential flexibility keeping the needs of the second language learners.

\section{References:}

Aliazadeh, Mitra.(2016). The Impact of Motivation on English Language Learning. International Journal of Research in English Education, Vol.1, pp.11-15. 
Bernaus, Merce (1995). The Role of Motivation in the learning of English Language, Semantic Scholar, pp.1-30.

Carrio-Pastor, Maria Luisa and Mestre, M Eva.(2013). Motivation in Second Language Acquisition. Procedia: Social and Behavioral Sciences, Vol.116, pp.240-244.

DeLoache, J. (1995). Early Symbol Understanding and Use. In D. Medin (ed.), The Psychology of Learning and Motivation: Advances in Research and Theory. Orlando, FL: Academic Press. 33: 65-114.

Emmons RA, King LA. (1988). Conflict among personal strivings: Immediate and long-term implications for psychological and physical well-being, Journal of Personality and Social Psychology. pp.1040-1048.

Gardner, R.C. (1985). Social Psychology and Second Language Learning: The Role of Attitudes and Motivation. Edward Arnold, London.

Gomleksiz, M. N. (2001). The effects of age and motivation factors on second language acquisition. Firat University Journal of Social Science, Vol.11,pp. 217-224.

Liu, Xiongyi \& Wang, Lih-Ching Chen (2017). Motivation, Learning Strategies, and Language Competency in a Technology Facilitated Chinese as a Second Language Classroom, Chinese Language Teaching Methodology and Technology, Vol. 1, pp. 1-8.

Low, Shawn \& Reinders, Hayo (2011). Key Concepts in Second Language Acquisition. Macmillan Education, UK.

Mahadi, T.S. Tengku and Jafari, Sepideh.M.(2012). Motivation, Its Types, and Its Impacts in Language Learning, International Journal of Business and Social Science, Vol.3,pp.230-235.

Mohammadi, Maryam. et al. (2010). The Relationship between Motivational Systems and Second Language Learning. Procedia Social and Behavioral Sciences, Vol.2,pp. 3258-3262.

Oxford, R. and Nyikos, M. (1989). Variables Affecting Choice of Language Learning Strategies by University Students. Modern Language Journal, Vol.73, pp.291-300.

Saito, Kazuya, et al. (2017). A Longitudinal Investigation of the Relationship between Motivation and Late Second Language Speech Learning in Classroom Settings, Language and Speech, https://doi.org/10.1177/0023830916687793

Schmidt, Richard et al. (1996). Motivation, strategy use, and pedagogical preferences in foreign language learning. In Z. Dörnyei \& R. Schmidt (Eds.), Motivation and second language acquisition, pp. 313-359).

Saleem, Jahangir.(2014). The Attitudes and Motivation of Swedish Upper Secondary School Students towards Learning English as a Second-Language. (Unpublished Doctoral Thesis)

Tarhan, Hakan, and Balban, Sena. (2014). Motivation, Learner Identity and Language Learning. International Journal on New Trends in Education and Their Implications, Vol.5, pp.183-197.

Ushida, Eiko.(2005). The Role of Students' Attitudes and Motivation in Second Language Learning in Online Language Courses. CALICO Journal, Vol.23, pp.49-78. 
Zaman, Jenifara.(2015). Role of Motivation in Second Language Learning: A study of Private University Students in Bangladesh. (Unpublished Doctoral Thesis)

\section{Authors:}

First Author: Sambhunath Maji, M.A. P.G.D.G.C, Sidho-Kanho-Birsha University, Purulia, West Bengal. Email: Sambhunath00746@gmail.com

Second Author: Prof. Birbal Saha, M.A. (Triple), M.Ed, Ph.D, Sidho-Kanho-Birsha University, Purulia, West Bengal. Email: birbalsaha@gmail.com 